\title{
Microvascular decompression for the treatment of neurogenic hypertension with trigeminal neuralgia
}

\author{
Wenchao $\mathrm{Lu}^{1 *+} \mathbb{D}$, Hui Wang ${ }^{2+}$, Zhongnan Yan'1, Yuangang Wang ${ }^{1}$ and Hongmin Che ${ }^{1}$
}

\begin{abstract}
Background: To evaluate the efficacy of microvascular decompression (MVD) in reducing hypertension (HTN) in hypertensive patients with trigeminal neuralgia (TN).

Methods: The clinical data of 58 cases of neurogenic HTN with TN treated in our hospital were retrospectively reviewed. Preoperative MR revealed abnormal blood pressure in the left rostral ventrolateral medulla (RVLM) and the posterior cranial nerve root entry zone (REZ). The patients were divided into control group: only trigeminal nerve was treated with MVD; experimental group: trigeminal nerve, RVLM and REZ were treated with MVD at the same time. The patients were followed up for 6 months to 1 year to observe the changes of blood pressure.

Results: There was no significant difference in gender, age, course of TN, course of HTN, grade of HTN and preoperative blood pressure between the two groups. After operation, the effective rate of HTN improvement with MVD was $32.1 \%$ in the control group. There was no significant difference in the preoperative and post operative blood pressure. $\left(P \triangle_{S B P}=0.131 ; P \triangle_{B D P}=0.078\right)$. In the experimental group, the effective rate was $83.3 \%$. The postoperative blood pressure was significantly lower than preoperative values. $\left(\mathrm{P} \Delta_{\mathrm{SBP}}<0.001\right.$; $\left.\mathrm{P} \triangle_{\mathrm{DBP}}<0.001\right)$.

Conclusions: MVD is an effective treatment for neurogenic HTN. However, the criteria for selecting hypertensive patients who need MVD to control their HTN still needs to be further determined. Possible indications may include: left trigeminal neuralgia, neurogenic HTN; abnormal blood pressure compression in the left RVLM and REZ areas on MR; and blood pressure in these patients can not be effectively controlled by drugs.
\end{abstract}

Keywords: Neurogenic hypertension, microvascular decompression, Trigeminal neuralgia, Rostral ventrolateral medulla

\section{Background}

With the improvement of people's living standards and the aging of our society, HTN is one of the diseases that seriously threaten human health, its incidence is increasing year by year. If there is no effective treatment, it often leads to serious complications and even death [1]. Most patients with HTN can get ideal control of blood pressure through systematic and regular medication. However, some patients still have difficulty to effectively control blood pressure after

\footnotetext{
*Correspondence: luwenchao1985@163.com

Wenchao Lu and Hui Wang are Co-first author.

'Department of Neurosurgery, the Xi'an Gaoxin Hospital, No.16 Tuanjie South

Road, Xi'an 710061, Shaanxi Province, China

Full list of author information is available at the end of the article
}

combined antihypertensive drugs. Jannetta et al. [2] suggested that the cause of HTN may be due to the left rostral ventrolateral medulla (RVLM) and the REZ. Due to pulsatile compression, if the vascular compression is relieved, HTN can be effectively relieved and treated. At present, microvascular decompression (MVD) has become a special treatment for TN by separating the responsible vessels from the nerves and relieving the compression of the blood vessels [3]. However, it is difficult to select patients for MVD only because of HTN. We retrospectively analyzed the clinical outcomes of 58 neurogenic HTN with TN undergoing MVD. Among them, 30 patients underwent MVD in the left RVLM and REZ regions simultaneously. Satisfactory results were achieved after operation.

(c) The Author(s). 2019 Open Access This article is distributed under the terms of the Creative Commons Attribution 4.0 International License (http://creativecommons.org/licenses/by/4.0/), which permits unrestricted use, distribution, and 


\section{Methods}

\section{Inclusion and exclusion criteria}

(1) Inclusion criteria: (1)Primary left TN with typical clinical presentation, without any specific etiology determined. (2) According to criteria for diagnosis of HTN, a baseline systolic pressure greater than 140 $\mathrm{mmHg}$ and a baseline diastolic pressure greater than $90 \mathrm{mmHg}$ [4]. (3)The combined use of antihypertensive drugs (calcium antagonists, diuretics, angiotensin converting enzyme inhibitors and betareceptor antagonists) has poor therapeutic effect. (4) Preoperative MR confirms the presence of vascular compression in the left RVLM and REZ regions.

(2) Exclusion criteria: (1) Secondary TN; (2) Secondary HTN, including renal HTN, endocrine HTN and drug-induced HTN; (3)Combined with heart failure or arrhythmia, antihypertensive drugs cannot be stopped; (4)Alcoholism, drug abuse, mental disorders, irregular life; (5)Oral antihypertensive drugs are irregular; (6) Other surgical contraindications for MVD.

\section{General situation}

From January 2009 to October 2018, 58 patients with left TN with HTN were included. After admission, blood pressure was monitored for at least three consecutive days. Preoperative oral or intravenous medication was used to control blood pressure at an acceptable level during surgery. (systolic blood pressure $<150 \mathrm{mmHg}$, diastolic blood pressure $<95 \mathrm{mmHg}$ ). Among them, 30 patients $(17$ males and 13 females, aged $60.6 \pm 9.4$ years) received microvascular decompression of the left trigeminal nerve and RVLM and REZ area as experimental group with the consent of the patients themselves and their families, while microvascular decompression of the left trigeminal nerve was performed only in 28 patients (18 males and 10 females, aged $61.2 \pm 9.6$ years) as the control group.

\section{Imaging examination}

All patients underwent preoperative MRI scanning. The relationship between blood vessels and trigeminal nerve, RVLM and REZ was evaluated by three-dimensional timeof-flight magnetic resonance angiography (3D-TOFMRA). If there was a possibility of contact or compression, it was positive for MRI. Two radiologists would evaluate the results individually. When the evaluation results were inconsistent, it would be decided after discussion.

\section{Surgical methods}

All patients were treated by left suboccipital retrosigmoid approach. Routine craniotomy was performed to expose the posterior edge of sigmoid sinus and the inferior edge of transverse sinus. The open mastoid air chamber was sealed with bone wax to prevent cerebrospinal fluid fistula. The dura mater was cut off and sharp separation was performed under the operating microscope. The occipital cistern, cerebellomedullary cistern and pontine cistern were opened. In the control group, only trigeminal nerve decompression was performed to free the responsible artery, and Teflon cotton was inserted to isolate it from the initial segment of the brain nerve root. In the experimental group, the trigeminal nerve was decompressed, the responsible artery was free, and the appropriate size of Teflon cotton was inserted to isolate the trigeminal nerve from the initial segment of the brain nerve root. In the same way, RVLM and REZ areas were explored. According to the relationship between vessels and RVLM and REZ areas, the responsible arteries were isolated and separated from the initial segment of the brain nerve root by inserting Teflon cotton of appropriate size. There was no obvious bleeding in the operative field and the dural incision was tightly sutured and the muscles, cap aponeurosis and scalp were sutured layer by layer. All operations were performed by the same surgical team.

\section{Blood pressure monitoring}

(1) After admission, the blood pressure under the condition of no medication was monitored in the morning for at least three consecutive days. (after completing blood pressure measurement, routine medication was continued). The mean blood pressure was taken as preoperative blood pressure. (2) Blood pressure in the morning without medication as monitored for 3 consecutive days in each review month (1 month, 3 months, 6 months and 12 months) after surgery respectively. The mean blood pressure was taken as the blood pressure of the review month. (3) After operation, blood pressure was measured three times in different days without change of taking antihypertensive drugs. If systolic blood pressure $(\mathrm{SBP})<140$ $\mathrm{mmHg}$ or diastolic blood pressure (DBP) $<90 \mathrm{mmHg}$, Antihypertensive drugs start to reduce or even stop drugs.

\section{Efficacy evaluation}

According to the extent of blood pressure decline and the degree of relief of symptoms, the therapeutic effect was judged as follows: (1). Cure: after the patient completely stopped using antihypertensive drugs, systolic blood pressure $<140 \mathrm{mmHg}$, and diastolic blood pressure $<90$ mmHg; (2). marked effect: systolic and diastolic blood pressure, one of which decreased to normal level or systolic blood pressure $<30 \mathrm{mmHg}$ and diastolic blood pressure decreased $<10 \mathrm{mmHg}$; (3). Effective: Systolic blood pressure decreased $<30 \mathrm{mmHg}$ and diastolic blood pressure decreased $<10 \mathrm{mmHg}$, the clinical symptoms of HTN were relieved, and the dosage of antihypertensive drugs was reduced. (4). Invalidity: The clinical symptoms of HTN were not relieved, and the systolic and diastolic 
blood pressures were not changed or even increased compared with those before operation.

Effectiveness $=($ cure + marked effect + effective $) /$ total number $\times 100 \%$.

\section{Statistical methods}

Data was analyzed using statistical product and service solutions software version 22.0. Continuous variables were expressed as mean \pm standard deviation or median. Differences between variables were evaluated using the independent samples t-test. Categorical variables were expressed as a ratio (\%), and differences between variables were compared using the chi-squared test. Data was deemed significant if $P<0.05$ for all tests.

\section{Results}

1. Comparison of basic data of two groups: There was no significant difference in the age, sex, course of HTN, duration of TN, grade of HTN, preoperative systolic and diastolic blood pressure between the experimental group and the control group $(P>$ 0.05), as shown in Table 1.

2. The symptoms of $\mathrm{TN}$ disappeared after operation in all patients.

The changes of blood pressure after operation are shown in Table 2 and Fig. 1. The blood pressure of the two groups was lower than that before operation. There were no significant differences in SBP and DBP between the preoperative and the 12 months after surgery in the control group. SBP and DBP in the experimental group decreased significantly at 12 months after operation compared with those before operation, and the difference was statistically significant.
3. According to the blood pressure after operation, the control group: 2 cases (7.1\%) were cured, 3 cases (10.7\%) were marked effect, 4 cases (14.3\%) were effective, 19 cases $(67.9 \%)$ were invalidity, and the effective rate was $32.1 \%$. In the experimental group, 10 cases (33.3\%) were cured, 9 cases (30\%) were marked effect, 6 cases (20\%) were effective and 5 cases $(16.7 \%)$ were invalidity. The effective rate was $83.3 \%$, as shown in Table 3.

\section{Discussion}

HTN is one of the most common chronic diseases that threaten human health. It is also a major risk factor for cardiovascular and cerebrovascular diseases. Its complications, such as cerebral hemorrhage, have high disability and mortality rates. Therefore, the prevention and control of HTN is of great significance to the prevention of cardiovascular and cerebrovascular diseases. At present, the treatment of HTN is mainly drug treatment. However, some of the hypertensive patients only use antihypertensive drugs, the effect is often unsatisfactory. In 1979, Jannetta et al. [2] found that part of HTN was caused by abnormal arterial compression of the left RVLM and REZ area, which was called neurogenic HTN. After MVD in these hypertensive patients, blood pressure returned to normal in some patients, and some patients' blood pressure decreased significantly. It provides a new treatment for HTN. Since then, a large number of clinical studies have proved that MVD can significantly reduce blood pressure in patients with neurogenic HTN, or even reduce the types and dosage of antihypertensive drugs, or discontinue antihypertensive drugs $[5,6]$.

At present, although MVD treatment of neurogenic HTN has been recognized by international scholars, but there are few patients with neurogenic HTN treated with

Table 1 Comparison of clinical data between the two groups

\begin{tabular}{|c|c|c|c|}
\hline & Control Group $(n=28)$ & Experimental $\operatorname{Group}(n=30)$ & $P$ value \\
\hline Gender & & & 0.266 \\
\hline Male & 18 & 17 & \\
\hline Female & 10 & 13 & \\
\hline Age (year) & $61.2 \pm 9.6$ & $60.9 \pm 9.4$ & 0.582 \\
\hline Course of TN (year) & $11.5 \pm 3.3$ & $11.3 \pm 3.1$ & 0.749 \\
\hline Course of HTN (year) & $20.5 \pm 10.5$ & $19.8 \pm 11.2$ & 0.807 \\
\hline Classification of HTN & & & $0.837^{\mathrm{a}}$ \\
\hline Level I & 3 & 4 & \\
\hline Level II & 10 & 9 & \\
\hline Level III & 15 & 17 & \\
\hline \multicolumn{4}{|l|}{ Preoperative BP } \\
\hline $\mathrm{SBP}(\mathrm{mmHg})$ & $181.0 \pm 20.4$ & $181.3 \pm 20.3$ & 0.815 \\
\hline $\mathrm{DBP}(\mathrm{mmHg})$ & $108.9 \pm 8.9$ & $108.2 \pm 10.2$ & 0.756 \\
\hline
\end{tabular}

${ }^{\mathrm{a}}$ From the merger of level II and III 
Table 2 Changes of BP before and after operation in two groups $(\mathrm{mmHg})$

\begin{tabular}{|c|c|c|c|c|}
\hline \multirow[t]{2}{*}{ Time } & \multicolumn{2}{|c|}{ Control Group } & \multicolumn{2}{|c|}{ Experimental Group } \\
\hline & SBP & DBP & SBP & DBP \\
\hline Preoperative & $181.0 \pm 20.4$ & $108.9 \pm 8.9$ & $181.3 \pm 20.3$ & $108.2 \pm 10.2$ \\
\hline One month after operation & $164.3 \pm 17.8$ & $100.8 \pm 11.2$ & $145.3 \pm 10.8$ & $98.4 \pm 12.5$ \\
\hline Three months after operation & $167.8 \pm 17.9$ & $101.5 \pm 13.4$ & $140.6 \pm 14.2$ & $92.1 \pm 10.7$ \\
\hline Six months after operation & $168.2 \pm 18.3$ & $102.7 \pm 15.8$ & $138.8 \pm 12.1$ & $90.2 \pm 11.3$ \\
\hline One year after operation & $172.4 \pm 21.6$ & $103.6 \pm 12.8$ & $136.5 \pm 11.6$ & $84.5 \pm 7.2$ \\
\hline$\triangle \mathrm{BP}$ & $8.6 \pm 5.8$ & $5.3 \pm 7.7$ & $44.8 \pm 9.5$ & $23.7 \pm 9.7$ \\
\hline$P$ value & 0.131 & 0.078 & $<0.001$ & $<0.001$ \\
\hline
\end{tabular}

$\triangle \mathrm{BP}$ :Changes of blood pressure before and after operation

MVD. The main reason is that there is no unified criterion for screening and diagnosis of neurogenic HTN patients. More importantly, most patients are unwilling to accept craniotomy because of HTN. However, MVD has been widely recognized in the treatment of TN. At the same time, through clinical observation, TN can also cause and/or aggravate HTN, which is mainly caused by long-term repeated pain stimulation, mental tension, anxiety, which makes the sympathetic nerve excited. Sympathetic nerve excitation not only acts on myocardial B receptor to accelerate heart rate and strengthen myocardial contraction, but also acts on peripheral blood vessel a receptor to make small arteries contract and peripheral blood vessel resistance increase, leading to increased blood pressure. In addition, long-term sympathetic nerve excitation can release norepinephrine through hypothalamus and peripheral sympathetic nerve endings, which can increase blood pressure [7] After MVD, the symptoms of TN disappeared, and then the tension and excitement smoothed, the sympathetic excitability gradually decreased to normal, and the blood pressure also decreased to normal [8]. Therefore, although there are abnormal blood pressure compressions in RVLM and REZ regions, repeated and long-term pain stimulation is also one of the causes of neurogenic HTN [7]. We found that patients with TN with HTN only performed trigeminal MVD, and their blood pressure decreased in varying degrees. The cure rate was 2 cases (7.1\%) and marked effective was 3 cases (10.7\%) and 4 cases (14.3\%) were effective and 19 cases (67.9\%) were invalidity. The total effective rate was $32.1 \%$.

Because the left medulla oblongata is oppressed by arteries and long-term pain stimulation in patients, which can lead to over excitation of sympathetic nervous system and hypertension [9]. Therefore, we believe that patients with neurogenic HTN combined with TN is the best surgical indications. For patients with trigeminal neuralgia combined with hypertension, the left trigeminal nerve and RVLM and REZ regions can be performed simultaneously, and the patients can obtain ideal curative effect and benefit. At present, the curative effect of MVD in the treatment of neurogenic HTN is different. The highest effective rate

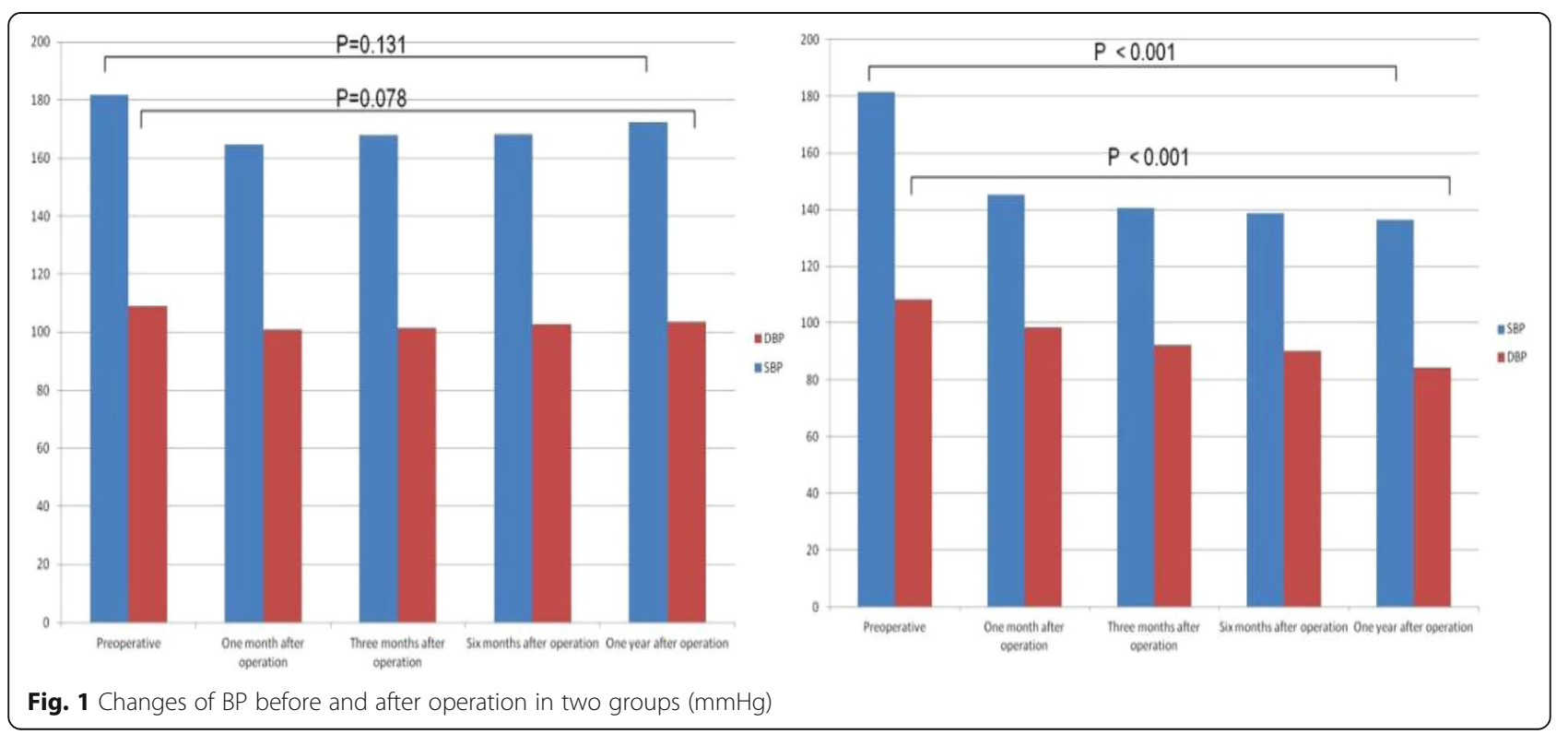


Table 3 Comparisons of surgical effects between two groups

\begin{tabular}{lll}
\hline Curative Effect & Control Group(\%) & Experimental Group(\%) \\
\hline Cure & $2(7.1)$ & $10(33.3)$ \\
Marked Effect & $3(10.7)$ & $9(30)$ \\
Effective & $4(14.3)$ & $6(20.0)$ \\
Invalidity & $19(67.9)$ & $5(16.7)$ \\
\hline
\end{tabular}

is $87.5 \%$, and the lowest is $23.8 \%$ [10]. Sindou et al. [11] conducted a retrospective study of 48 patients underwent MVD, 14 patients recovered normal blood pressure after operation, 14 patients were marked effect, 10 patients were effective. The total effective rate was $79.2 \%$. Geiger [12] et al. performed MVD in patients with neurogenic HTN, the postoperative effective rate was $87.5 \%$. We performed MVD on the trigeminal nerve and the left RVLM and REZ area simultaneously, and the blood pressure of the patients decreased effectively, the cure was: 10 cases (33.3\%), markedly effect: 9 cases (30\%), effective: 6 cases (20\%), invalidity: 5 cases $(16.7 \%)$. The total effective rate was $83.3 \%$. Compared with preoperative blood pressure, the change of blood pressure has significant statistical difference. The symptoms of cranial nerve compression disappeared and no serious complications occurred in all patients, which further confirmed the efficacy of MVD in the treatment of neurogenic HTN. And our efficiency is consistent with international research results.

Because most of the patients with primary TN complicated with neurogenic HTN are the elderly, they are more concerned about the risk of surgery. If the relationship between trigeminal nerve and medulla oblongata and peripheral blood vessels can be fully evaluated before operation, and the responsible blood vessels can be initially determined, it will be conducive to the operation. In 3DTOFMRA sequence images, the nerve and brain tissue showed equal signals, the peripheral blood vessels showed high signals, and the cerebrospinal fluid showed low signals. The contrast was clear. The relationship between peripheral blood vessels and nerves and brainstem could also be observed directly. The maximum density projection technique could also be used to realize arterial imaging to understand the origin and course of the responsible blood vessels [13]. It can provide an effective means for preoperative evaluation and screening.

A large number of clinical studies have confirmed that patients with neurogenic HTN are due to the compression of the left RVLM and REZ neurovascular areas [14-16]. MVD to relieve the vascular compression in the left RVLM and REZ is the treatment of etiology. Therefore, the patients we selected were all left TN patients with left RVLM and REZ neurovascular compression. Whether the right HTN RVLM and REZ neurovascular compression patients with MVD have the same efficacy requires further clinical study. Similarly, the long-term follow-up evaluation of MVD for hypertensive patients needs to be determined by a rigorous, multicenter, prospective and randomized clinical study. Only in these areas has made great progress, microvascular decompression can play an important role in the treatment of neurogenic HTN.

\section{Conclusions}

MVD is an effective treatment for neurogenic HTN. However, the criteria for selecting hypertensive patients still need to be further determined. In order to improve the efficacy of neurogenic HTN surgery, including the following indications as far as possible: left TN; neurogenic HTN; abnormal blood pressure compression in the left RVLM and REZ areas in high-resolution MR images; the blood pressure in these patients cannot be effectively controlled by combined antihypertensive drugs.

\section{Abbreviations}

3D-TOFMRA: three-dimensional time-of-flight magnetic resonance angiography; BP: Blood pressure; DBP: Diastolic blood pressure; HTN: Hypertension; MRI: Magnetic resonance imaging; MVD: Microvascular decompression; REZ: The posterior cranial nerve outgoing (entering) brainstem; RVLM: Rostral ventrolateral medulla; SBP: Systolic blood pressure; TN: Trigeminal neuralgia

\section{Acknowledgements}

We thank the nurses for providing useful advice and cooperation.

\section{Authors' contributions}

WC L: Identifying research topics; Confirm the results of statistical analysis; Complete the preliminary draft. H W: Data collection; Revision of manuscript. ZN Y: Data collection; Revision of manuscript. YG W: Data collection; Revision of manuscript. HM C: Data collection; Statistical analysis of data. All authors have read and approved the final manuscript, and ensure that this is the case.

\section{Funding}

No financial support was received for this study.

\section{Availability of data and materials}

The datasets used or analysed during the current study are available from the corresponding author on reasonable request.

\section{Ethics approval and consent to participate}

This study was approved by the Ethics Committee of our hospital (the Medical Ethics Committee of Xi'an Gaoxin Hospital Recommendation) and all patients signed informed consents.

\section{Consent for publication}

Not Applicable.

\section{Competing interests}

The authors declare that they have no competing interests.

\section{Author details}

'Department of Neurosurgery, the Xi'an Gaoxin Hospital, No.16 Tuanjie South Road, Xi'an 710061, Shaanxi Province, China. ${ }^{2}$ Department of Neurosurgery, the Xi'an Daxing Hospital, Xi'an, Shaanxi Province, China.

Received: 30 June 2019 Accepted: 11 December 2019

Published online: 27 December 2019

\section{References}

1. Gosmanova EO, Mikkelsen MK, Molnar MZ, Lu JL, Yessayan LT, KalantarZadeh K, Kovesdy CP. Association of Systolic Blood Pressure Variability with 
Mortality, coronary heart disease, stroke, and renal disease. J Am Coll Cardiol. 2016;68(13):1375-86.

2. Jannetta PJ, Gendell HM. Clinical observations on etiology of essential hypertension. Surg Forum. 1979:30:431-2.

3. Oesman C, Mooij JJ. Long-term follow-up of microvascular decompression for trigeminal neuralgia. Skull Base. 2011;21(5):313-22.

4. John M, Flack DC, Ernesto L. Schiffrin the new ACC/AHA hypertension guidelines for the prevention, detection, evaluation, and Management of High Blood Pressure in adults. Am J Hypertens. 2018;31(2):133-5.

5. Legrady P, Voros E, Bajcsi D, Fejes I, Barzo P, Abraham G. Observations of changes of blood pressure before and after neurosurgical decompression in hypertensive patients with different types of neurovascular compression of brain stem. Kidney Blood Press Res. 2013;37(4-5):451-7.

6. Sasaki S, Tanda S, Hatta T, Morimoto S, Takeda K, Kizu O, Tamaki S, Saito M, Tamura Y. Kondo A. Neurovascular decompression of the rostral ventrolateral medulla decreases blood pressure and sympathetic nerve activity in patients with refractory hypertension. J Clin Hypertens (Greenwich). 2011;13(11):818-20.

7. Feihl F, Liaudet L, Levy BI, Waeber B. Hypertension and microvascular remodelling. Cardiovasc Res. 2008;78(2):274-85.

8. Sasaki S, Tanda S, Hatta T, et al. Neurovascular decompression of the rostral ventrolateral medulla decreases blood pressure and sym pathetic nerve activity in patients with refractory hypertension. J Clin Hypertens. 2011; 13(11):818-20.

9. Kumagai $\mathrm{H}$, Oshima $\mathrm{N}$, Matsuura $\mathrm{T}$, et al. Importance of rostral ventrolateral medulla neurons in determining efferent sympathetic nerve activity and blood pressure. Hypertension Res. 2012;35(2):132-41.

10. Yamamoto I, Yamada S, Sato O. Microvascular decompression for hypertension-clinical and experimental study. Neurol Med Chir (Tokyo). 1991:31(1):1-6.

11. Sindou M, Brinzeu MM. A hypertension of neurogenic origin: effect of microvascular decompression of the CN IX-X root entry/exit zone and ventrolateral medulla on blood pressure in a prospective series of 48 patients with hemifacial spasm associated with essential hypertension. J Neurosurgery. 2015;123(6):1405-13.

12. Geiger $H$, Naraghi R, Schobel HP. Decrease of blood pressure by ventrolateral medullary decompression in essential hypertension. Lancet. 1998;352(9126):446-9.

13. Cai J, Xin ZX, Zhang YQ, Sun J, Lu JL, Xie F. Diagnostic value of 3D time-offligHTN MRA in trigeminal neuralgia. J Clin Neurosci. 2015;22(8):1343-8.

14. Ceral J, Zizka J, Elios P, et al. Neurovaseular compression in essential hypertension:cause, consequence or unrelated finding? I Hum Hypertens. 2007;21:179-81.

15. Naraghi R, Fahlbusch R. Microvascular decompression of the left lateral medulla oblongata for severe refractory neurogenic hypertension. Neurosurgery. 1999:45(4):955.

16. Boogaarts HD, Menovsky T, de Vries J, Verbeek AL, Lenders JW, Grotenhuis JA. Primary hypertension andneurovascular compression:a meta-analysis of magnetic resonance imaging studies. J Neurosurg. 2012;116(1):147-56.

\section{Publisher's Note}

Springer Nature remains neutral with regard to jurisdictional claims in published maps and institutional affiliations.

Ready to submit your research? Choose BMC and benefit from:

- fast, convenient online submission

- thorough peer review by experienced researchers in your field

- rapid publication on acceptance

- support for research data, including large and complex data types

- gold Open Access which fosters wider collaboration and increased citations

- maximum visibility for your research: over $100 \mathrm{M}$ website views per year

At $\mathrm{BMC}$, research is always in progress.

Learn more biomedcentral.com/submissions 